Check for updates

Cite this: RSC Adv., 2018, 8, 26707

\title{
Simultaneous electrochemical determination of levodopa and piroxicam using a glassy carbon electrode modified with a $\mathrm{ZnO}-\mathrm{Pd} / \mathrm{CNT}$ nanocomposite
}

\begin{abstract}
Hassan Karimi-Maleh, (D) *a Iran Sheikhshoaie (iD b and Ali Samadzadeh ${ }^{b}$
A highly conductive electrochemical sensor was constructed for the simultaneous electrochemical determination of levodopa and piroxicam by modification of a glassy carbon electrode with a $\mathrm{ZnO}-\mathrm{Pd} /$ CNT nanocomposite (GCE/ZnO-Pd/CNTs). The ZnO-Pd/CNT nanocomposite was synthesized by the sol-gel procedure and was characterized by EDAX, MAP and SEM. The sensor was shown to improve the oxidation signal of levodopa and piroxicam by $\sim 70.2$-fold and $\sim 41.5$-fold, respectively. This marks the first time that the electrochemical behavior of levodopa and piroxicam have been investigated at the surface of GCE/ZnO-Pd/CNTs. The voltammogram showed a quasi-reversible signal and an irreversible redox signal for electro-oxidation of levodopa and piroxicam, respectively. The GCE/ZnO-Pd/CNTs showed a linear dynamic range of 0.6 to $100.0 \mu \mathrm{M}$ (at a potential of $\sim 180 \mathrm{mV}$ ) and 0.1 to $90 \mu \mathrm{M}$ (at a potential of $\sim 480 \mathrm{mV}$ ) with detection limits of 0.08 and $0.04 \mu \mathrm{M}$ for the determination of levodopa and piroxicam, respectively. GCE/ZnO-Pd/CNTs were then applied for the determination of levodopa

and piroxicam in real samples.
\end{abstract}

Received 22nd April 2018

Accepted 11th July 2018

DOI: $10.1039 / \mathrm{c} 8 \mathrm{ra0} 4460 \mathrm{e}$

rsc.li/rsc-advances

\section{Introduction}

Electrochemical methods have been proposed as highly powerful and portable means of analyzing drugs and biological samples. ${ }^{1-9}$ Simple modifications have allowed the development of a range of mediators for sensitivity analysis, simultaneous analysis and ease of operation of electroactive compounds and in electrochemical sensors for determination of drugs and biological samples. ${ }^{10-15}$ Moreover, modification of electrochemical sensors with conductive mediators like nanomaterials, ionic liquids and conductive polymers can make possible the analysis of drugs and biological samples at the nanomolar level..$^{\mathbf{8 1 6 - 2 0}}$

Nanomaterials show unique properties and have been suggested as effective materials in different fields. ${ }^{21-26}$ Nanomaterials, especially carbon-based modified nanocomposites, are good choices as conductive mediators for modification of an electrode surface because they offer high electrical conductivity and a high surface area. ${ }^{27-30}$ The unique electrical conductivity of carbon nanotube-based nanocomposites makes them possible materials with which to fabricate sensitive voltammetric sensors for electroactive materials. ${ }^{31-35}$ Also, the ability of

\footnotetext{
${ }^{a}$ Department of Chemical Engineering, Laboratory of Nanotechnology, Quchan University of Technology, Quchan, Iran. E-mail: H.karimi.maleh@gmail.com; Tel: $+98-9112540112$

${ }^{b}$ Department of Chemistry, Shahid Bahonar University, Kerman, Iran
}

carbon nanotubes (CNTs) to function with different groups makes it possible the fabrication of selective electrochemical sensors.

Tavana et al. used CNTs as conductive mediators for modification of carbon paste electrodes as electrochemical sensors to simultaneously determine the presence of epinephrine and acetaminophen in biological and drug samples. ${ }^{36} \mathrm{Wu}$ et al. used CNTs modified with ionic liquid polymers and Pt and PtRu nanoparticles as conductive mediators for methanol electrooxidation. ${ }^{37}$

Levodopa is a catechol derivative and a powerful drug for treating Parkinson's disease. It has also been suggested for treatment of muscular problems after the intake of fluphenazine and chlorpromazine. ${ }^{38,39}$ However, consuming high levels of levodopa can cause seizures, unusual changes in mood or behavior and suicidal thoughts. This means that it is very important to control the use of levodopa in patients undergoing treatment.

Piroxicam (ibuprofen) is a nonsteroidal anti-inflammatory drug (NSAID). It is usually prescribed to reduce pain and swelling and can increase the risk of heart attack or stroke. Teema et al. demonstrated the role of piroxicam in protecting nigral neurons and delaying the development of levodopainduced dyskinesia. ${ }^{40}$

Because of the effect of piroxicam on levodopa activity and the importance of the analysis of these drugs, the current study was undertaken to fabricate a highly sensitive and selective 
voltammetric sensor for their simultaneous determination. To achieve this goal, a glassy carbon electrode modified with $\mathrm{ZnO}-$ $\mathrm{Pd} / \mathrm{CNT}$ nanocomposite was suggested as an electrochemical sensor. The GCE/ZnO-Pd/CNTs showed high sensitivity for the simultaneous determination of piroxicam and levodopa in real samples. To the best of our knowledge, this is the first electrochemical sensor suggested for the simultaneous determination of piroxicam and levodopa.

\section{Experiments}

\section{Chemical and apparatus}

Levodopa and piroxicam (Merck) and zinc nitrate, CNTs, $\mathrm{Na}_{2}$ $\mathrm{PdCl}_{4}$ and sodium hydroxide (Sigma-Aldrich) and used for the synthesis of ZnO-Pd/CNTs. A PalmSens BV potentiostat and galvanostat analyzer was used for all electrochemical investigations. For voltammetric investigations, $\mathrm{Ag} / \mathrm{AgCl} / \mathrm{KCl}$ was used as a reference electrode, GCE/ZnO-Pd/CNT as a working electrode and $\mathrm{Pt}$ wire as an axillary electrode.

\section{Synthesis of ZnO-Pd/CNTs}

ZnO-Pd nanoparticles were synthesized using the following procedure: $0.2 \mathrm{~g}$ starch was dissolved in $20 \mathrm{~mL}$ hot distilled water $\left(40^{\circ} \mathrm{C}\right)$ for $10 \mathrm{~min}$ and then $50 \mathrm{~mL}$ zinc nitrate $(0.5 \mathrm{M})$ was added to the solution. Next, $4.0 \mathrm{mg} \mathrm{Na}_{2} \mathrm{PdCl}_{4}$ was added and the solution was stirred for $30 \mathrm{~min}$ at room temperature. The $\mathrm{pH}$ of the mixture was increased to 9.0 by adding 0.1 sodium hydroxide and stirring for $2.0 \mathrm{~h}$. The resulting white gel was washed and filtered continually in distilled water ( $\mathrm{pH} 7.0)$, dried at $80{ }^{\circ} \mathrm{C}$ for $60 \mathrm{~min}$ and calcinated at $450{ }^{\circ} \mathrm{C}$ for $4 \mathrm{~h}$.

The $2.0 \mathrm{mg} \mathrm{ZnO}-\mathrm{Pd}$ nanoparticle was dispersed in $2.0 \mathrm{~mL}$ $\mathrm{N}, \mathrm{N}$-dimethylformamide and ultrasonicated for $100 \mathrm{~min}$. Next, $10 \mu \mathrm{L} \mathrm{ZnO-Pd} \mathrm{nanoparticle} \mathrm{suspension} \mathrm{was} \mathrm{added} \mathrm{to} 90 \mu \mathrm{L}$ multiwall-CNT suspension and ultrasonicated for $100 \mathrm{~min}$ to obtain the ZnO-Pd/CNT nanocomposite.

\section{Construction of GCE/ZnO-Pd/CNTs}

After cleaning the glassy carbon electrode with alumina powder and distilled water, $15 \mu \mathrm{L}$ ZnO-Pd/CNT suspension

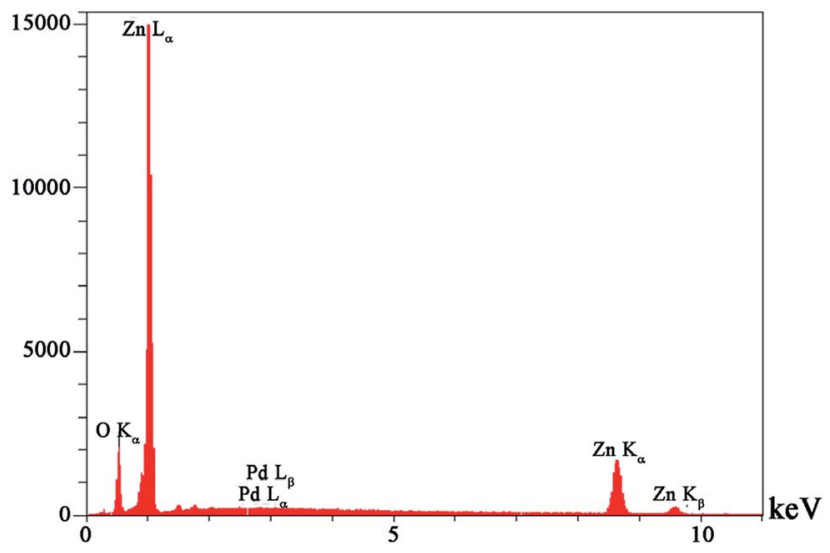

Fig. 1 EDAX analysis of synthesized $\mathrm{ZnO}-\mathrm{Pd}$ nanoparticles.

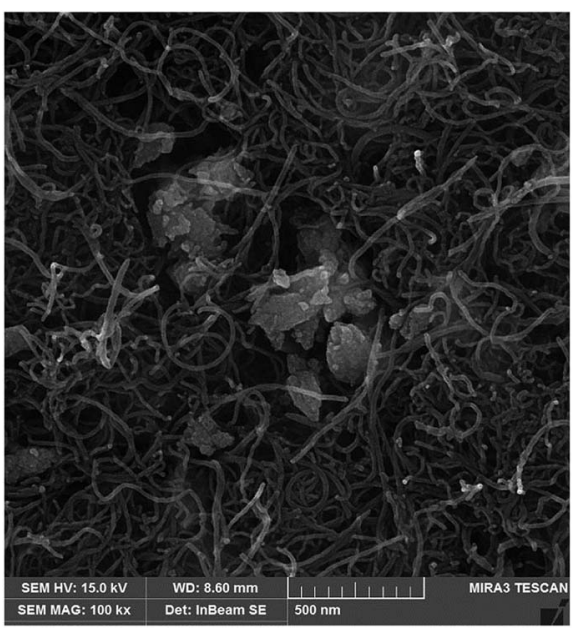

Fig. 2 SEM image of synthesized $\mathrm{ZnO}-\mathrm{Pd} / \mathrm{CNTS}$ nanocomposite relative to presence of $\mathrm{ZnO}-\mathrm{Pd}$ at surface carbon nanotubes.

was applied to the glassy carbon electrode and it was dried at room temperature. The GCE/ZnO-Pd/CNTs were used as working electrodes for voltammetric investigations.

\section{Preparation of real samples}

Human urine and blood samples were collected from the corresponding author as a healthy man. Five $\mathrm{mL}$ of the urine sample was centrifuged for $65 \mathrm{~min}$ at $4000 \mathrm{rpm}$ and then filtered through a $0.45 \mu \mathrm{m}$ filter. The filtered urine was used for real sample analysis. About $5 \mathrm{~mL}$ blood serum was diluted with $5 \mathrm{~mL}$ phosphate buffer solution and used for real sample analysis.

\section{Results and discussion}

\section{Characterization of ZnO-Pd/CNTs}

Fig. 1 shows the results of EDAX analysis of the $\mathrm{ZnO}-\mathrm{Pd}$ nanoparticle synthesized in this work. The presence of $\mathrm{Zn}, \mathrm{O}$ and $\mathrm{Pd}$

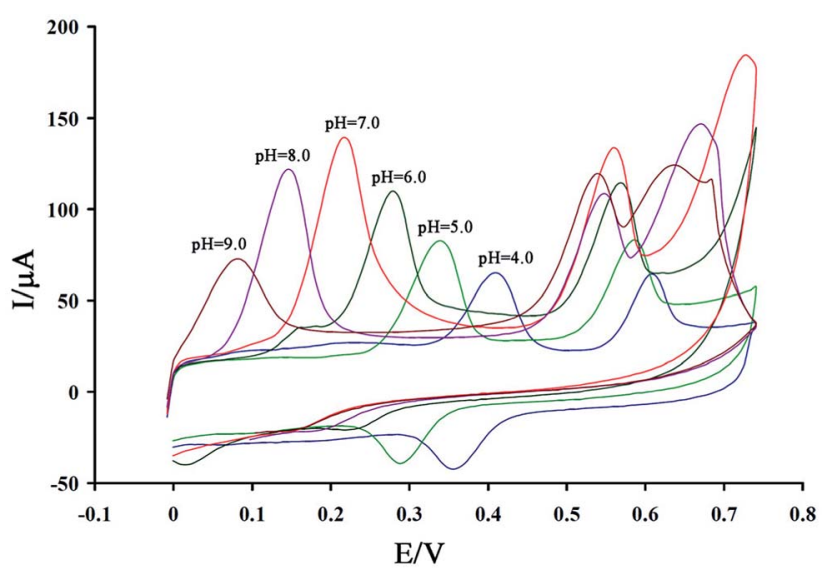

Fig. 3 Cyclic voltammograms of solution containing $200 \mu \mathrm{M}$ levodopa and $100 \mu \mathrm{M}$ piroxicam at a surface of GCE/ZnO-Pd/CNTs in the 6 different $\mathrm{pHs}(\mathrm{pH}=4.0, \mathrm{pH}=5.0, \mathrm{pH}=6.0, \mathrm{pH}=7.0, \mathrm{pH}=8.0$ and $\mathrm{pH}=9.0$ ). 

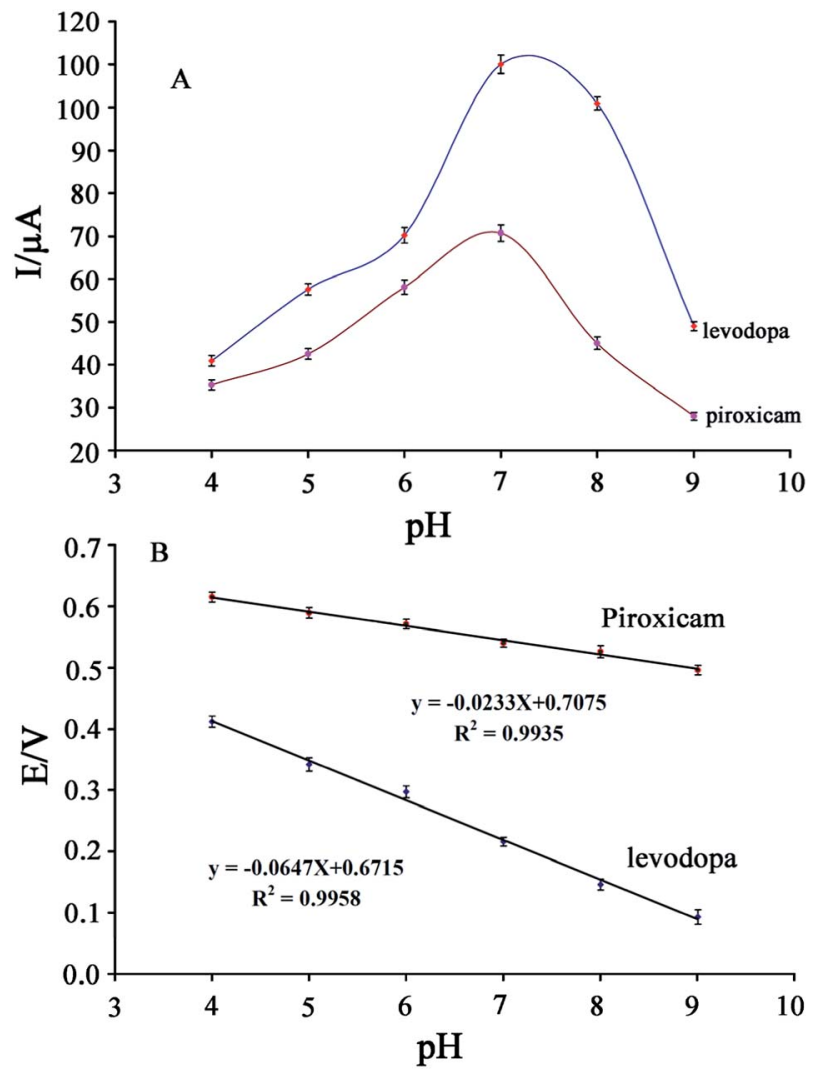

Fig. 4 (A) The plot of oxidation current vs. $\mathrm{pH}$ for solution containing $200 \mu \mathrm{M}$ levodopa and $100 \mu \mathrm{M}$ piroxicam at a surface of GCE/ZnO-Pd/ CNTs in the $\mathrm{pH}$ range 4.0-9.0 $(n=4)$. (B) The plot of oxidation peak potential vs. $\mathrm{pH}$ for solution containing $400 \mu \mathrm{M}$ levodopa and $200 \mu \mathrm{M}$ piroxicam at a surface of $\mathrm{GCE} / \mathrm{ZnO}-\mathrm{Pd} / \mathrm{CNTs}$ in the $\mathrm{pH}$ range 4.0-9.0 $(n=4)$.

elements confirm the purity of the ZnO-Pd nanoparticle. Fig. 2 shows the SEM image of the ZnO-Pd/CNTs. As seen, the ZnOPd nanoparticles decorate the surface of the CNTs.

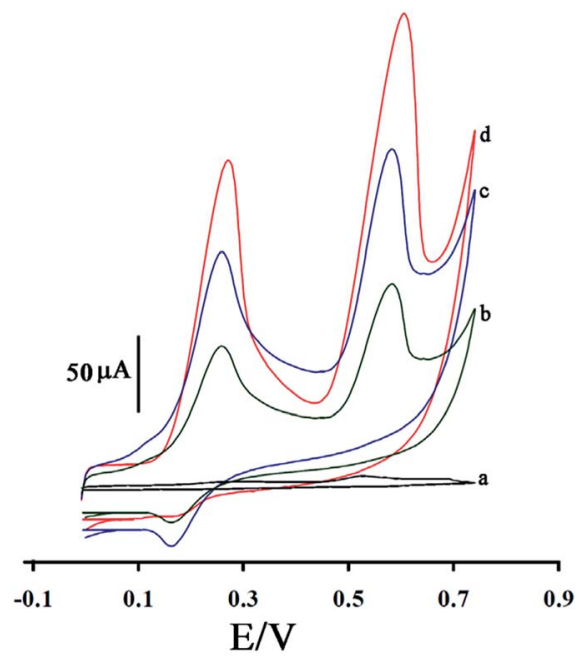

Fig. 5 The cyclic voltammograms of solution $(\mathrm{pH}=7.0)$ containing of $400 \mu \mathrm{M}$ levodopa and $200 \mu \mathrm{M}$ piroxicam at a surface of GCE (a); GCE/ CNTs (b); GCE/ZnO/CNTs (c) and GCE/ZnO-Pd/CNTs (d).

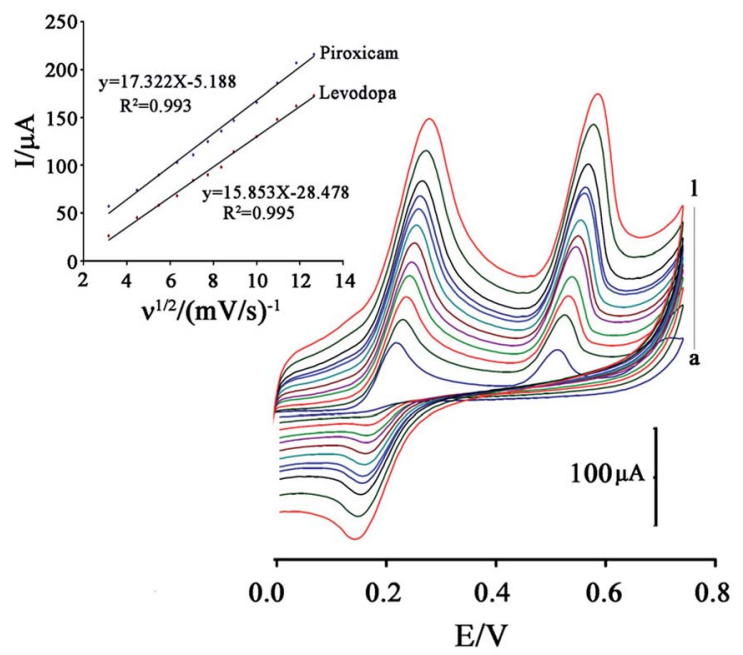

Fig. 6 The cyclic voltammograms of solution containing of $200.0 \mu \mathrm{M}$ levodopa and $120.0 \mu \mathrm{M}$ piroxicam at a surface of GCE/ZnO-Pd/CNTs at a scan rate (a) 10; (b) 20; (c) 30; (d) 40; (e) 50; (f) 60; (g) 70; (h) 80; (i) 100; (g) 120; (k) 140 and (l) $160 \mathrm{mV} \mathrm{s}^{-1}$ and $\mathrm{pH}=7.0$.

\section{Electrochemical oxidation of levodopa and piroxicam at GCE/ ZnO-Pd/CNT surface}

Studies show that electro-oxidation of levodopa and piroxicam is dependent on proton and electron exchange and that optimization of the $\mathrm{pH}$ value is very important for simultaneous analysis of these drugs. A cyclic voltammogram of a solution containing $200 \mu \mathrm{M}$ levodopa and $100 \mu \mathrm{M}$ piroxicam was recorded at the surface of the GCE/ZnO-Pd/CNTs at a pH of 4.0-9.0 (Fig. 3).

As seen, the peak oxidation potential of levodopa and piroxicam shifted to negative values with an increase in $\mathrm{pH}$, confirming that electro-oxidation of these drugs is relative to proton exchange. The peak oxidation current of levodopa and piroxicam increased with an increase in $\mathrm{pH}$ from 4.0 to 7.0 and decreased thereafter (Fig. 4A). Fig. 4B plots the oxidation potential of levodopa and piroxicam versus $\mathrm{pH}$. A decreasing

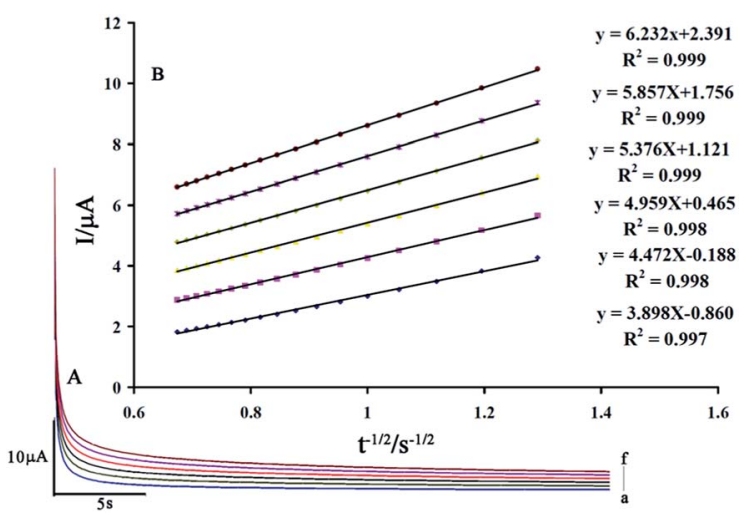

Fig. 7 (A) Chronoamperograms obtained at the GCE/ZnO-Pd/CNTs in the presence of (a) 100; (b) 200; (c) 300; (d) 400; (e) 500 and (f) $600 \mathrm{M}$ levodopa at $\mathrm{pH}$ 7.0. (B) Plots of $/$ vs. $t^{-1 / 2}$ obtained from chronoamperometry. 


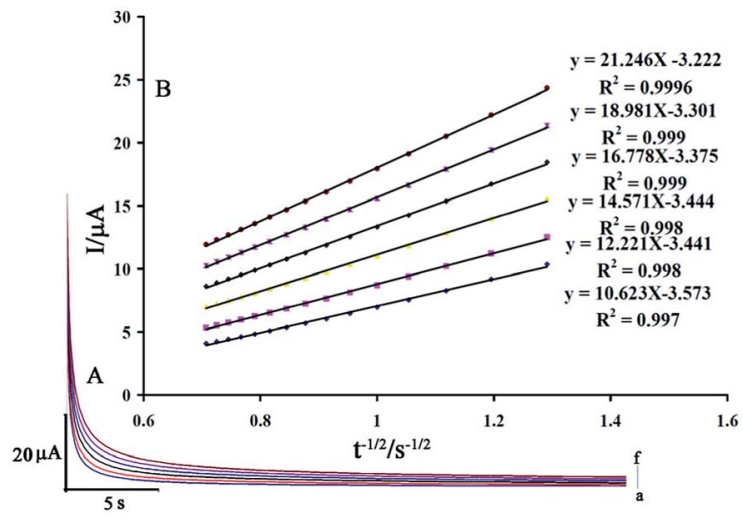

Fig. 8 (A) Chronoamperograms obtained at the GCE/ZnO-Pd/CNTs in the presence of (a) 100; (b) 200; (c) 300; (d) 400; (e) 500 and (f) $600 \mathrm{M}$ piroxicam at $\mathrm{pH}$ 7.0. (B) Plots of $/ \mathrm{vs}$. $t^{-1 / 2}$ obtained from chronoamperometry.

trend can be observed at $I=-0.0647 \mathrm{pH}+0.6715$ for levodopa and $I=-0.0233 \mathrm{pH}+0.7075$ for piroxicam. The slopes indicate an equal number of protons and electrons in the electrooxidation of levodopa and two electrons and one proton in the electro-oxidation of piroxicam.

Fig. 5 shows the cyclic voltammograms of the solution containing $400 \mu \mathrm{M}$ levodopa and $200 \mu \mathrm{M}$ piroxicam $(\mathrm{pH}=7.0)$ at the surface of the unmodified glassy carbon electrode (curve a); the glassy carbon electrode modified with multiwall CNTs (curve b); the glassy carbon electrode modified with $\mathrm{ZnO}$ nanoparticle-decorated multiwall CNTs (curve c); and the GCE/ ZnO-Pd/CNTs (curve d). The oxidation currents for levodopa and piroxicam were 3.1 and $7.48 \mu \mathrm{A}$, respectively, at the surface of the glassy carbon electrode. After the glassy carbon electrode was modified with CNTs, $\mathrm{ZnO} / \mathrm{CNTs}$ and $\mathrm{ZnO}-\mathrm{Pd} / \mathrm{CNTs}$, the oxidation currents of levodopa and piroxicam increased. The maximum oxidation currents for levodopa and piroxicam were detected at $\sim 217.63$ and $\sim 315.53 \mu \mathrm{A}$, respectively, on the surface of the GCE/ZnO-Pd/CNTs. The data confirms the high conductivity of ZnO-Pd/CNTs compared to the glassy carbon electrode and glassy carbon electrodes modified with CNTs and $\mathrm{ZnO} / \mathrm{CNTs}$. This suggests that $\mathrm{ZnO}-\mathrm{Pd} / \mathrm{CNTs}$ are highly

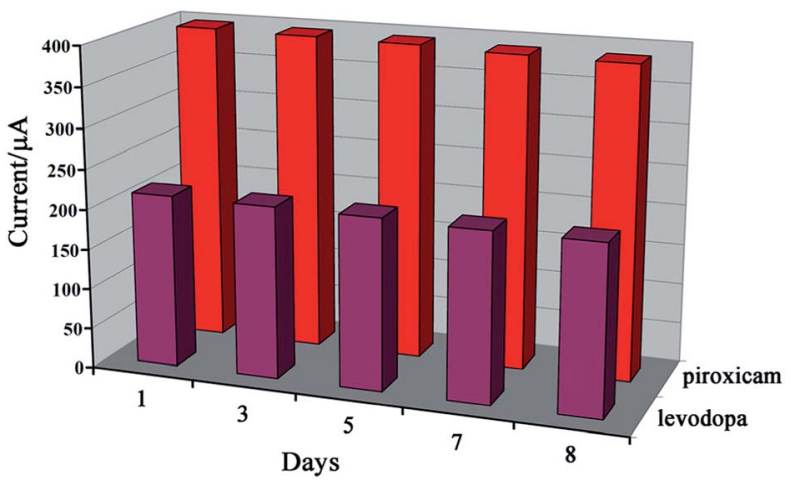

Fig. 9 The oxidation currents for levodopa and piroxicam obtained by cyclic voltammetric method in different days.

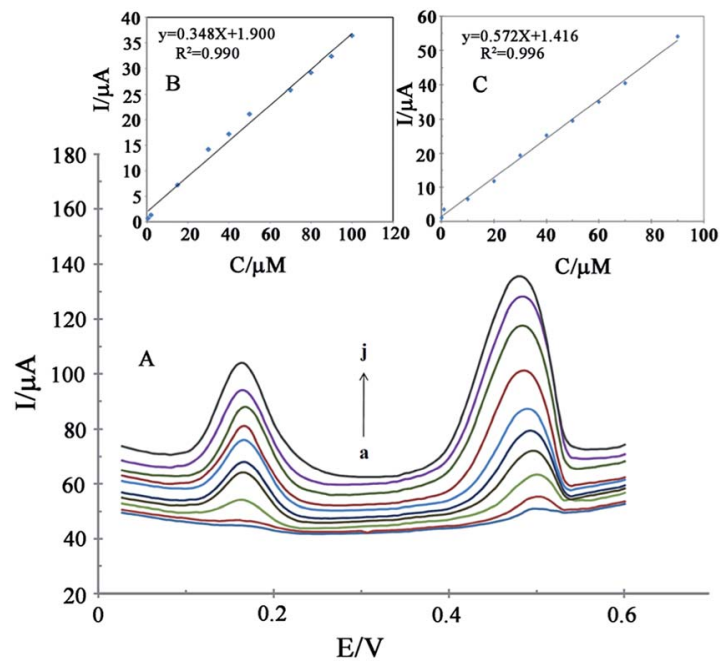

Fig. 10 (A) DPVs of GCE/ZnO-Pd/CNTs in containing different concentrations of levodopa and piroxicam; (a) $0.6+0.1 \mu \mathrm{M}$; (b) $2.0+$ $1.0 \mu \mathrm{M}$; (c) $15.0+10.0 \mu \mathrm{M}$; (d) $30.0+20.0 \mu \mathrm{M}$; (e) $40.0+30.0 \mu \mathrm{M}$; (f) $50.0+40.0 \mu \mathrm{M}$; (g) $70.0+50.0 \mu \mathrm{M}$; (h) $80.0+60.0$; (i) $90.0+70.0$ and (j) $100.0+90.0 \mu \mathrm{M}$, respectively. (B) The plots of the peak current as a function of levodopa concentration. (C) The plots of the peak current as a function of piroxicam concentration.

conductive mediators for the modification of glassy carbon electrodes to simultaneously determine levodopa and piroxicam.

The effect of scan rate on the oxidation potential and oxidation current of levodopa and piroxicam was investigated in a solution containing $200 \mu \mathrm{M}$ levodopa and $120 \mu \mathrm{M}$ piroxicam at a scan rate of 10.0 to $160.0 \mathrm{mV} \mathrm{s}^{-1}$.

Fig. 6 shows that an increase in scan rate caused the oxidation potential of levodopa and piroxicam to shift to positive values, confirming a quasi-reversible and irreversible process for electro-oxidation of levodopa and piroxicam, respectively, at the surface of the GCE/ZnO-Pd/CNTs.

The oxidation current of the two drugs showed a linear relationship with $\nu^{1 / 2}$ in all scan rate ranges, confirming diffusion of levodopa and piroxicam at the surface of the GCE/ZnOPd/CNTs (Fig. 6; inset).

The value of the diffusion coefficient $(D)$ for levodopa and piroxicam was determined by recording chronoamperomgrams of the drugs at step potentials of 350 and $650 \mathrm{mV}$ for levodopa and piroxicam, respectively. Fig. 7A and 8A show these for

Table 1 Interference study for the determination of $15.0 \mu \mathrm{M}$ levodopa $+10.0 \mu \mathrm{M}$ piroxicam ${ }^{a}$

\begin{tabular}{lll}
\hline Interference & Levodopa & Piroxicam \\
\hline Ascorbic acid & 500 & 800 \\
Alanine & 1000 & 900 \\
Histidine & 1000 & 1000 \\
Uric acid & 150 & 700 \\
Aspartic acid & 650 & 800 \\
$\mathrm{Li}^{+}, \mathrm{Na}^{+}, \mathrm{Cl}^{-}, \mathrm{Br}^{-}$ & 1000 & 1000
\end{tabular}

${ }^{a}$ The reported amount in the table is based on tolerance limits (W/W). 
Table 2 The real sample analysis of levodopa and piroxicam

\begin{tabular}{|c|c|c|c|c|c|c|c|c|}
\hline \multirow[b]{2}{*}{ Sample } & \multirow[b]{2}{*}{$\begin{array}{l}\text { Levodopa added } \\
(\mu \mathrm{M})\end{array}$} & \multirow[b]{2}{*}{$\begin{array}{l}\text { Piroxicam } \\
\text { added }(\mu \mathrm{M})\end{array}$} & \multicolumn{3}{|l|}{ Levodopa } & \multicolumn{3}{|l|}{ Piroxicam } \\
\hline & & & Found $(\mu \mathrm{M})$ & $\begin{array}{l}\text { Recovery } \\
(\%)\end{array}$ & RSD (\%) & Found $(\mu \mathrm{M})$ & $\begin{array}{l}\text { Recovery } \\
(\%)\end{array}$ & RSD (\%) \\
\hline \multirow[t]{3}{*}{ Blood serum } & - & - & $<$ Detection limit & - & - & $<$ Detection limit & - & - \\
\hline & 15.00 & 10.00 & $15.26 \pm 0.29$ & 101.7 & 1.9 & $10.5 \pm 0.16$ & 105 & 1.5 \\
\hline & 30.00 & 20.00 & $30.7 \pm 0.41$ & 102.3 & 1.3 & $20.6 \pm 0.26$ & 102.6 & 1.2 \\
\hline \multirow[t]{3}{*}{ Human urine } & - & - & $<\mathrm{DL}$ & - & - & $<\mathrm{DL}$ & - & - \\
\hline & 15.00 & 10.00 & $14.6 \pm 0.27$ & 97.3 & 5.7 & $9.4 \pm 0.3$ & 93.6 & 3.2 \\
\hline & 30.00 & 20.00 & $30.32 \pm 0.41$ & 101.0 & 1.4 & $19.4 \pm 0.23$ & 102 & 2.8 \\
\hline
\end{tabular}

different concentrations of levodopa and piroxicam (100-600 $\mu \mathrm{M})$, respectively, at the surface of the GCE/ZnO-Pd/CNTs.

The slopes of the Cottrell plots for levodopa and piroxicam (Fig. 7B and $8 \mathrm{~B}$ ) and the Cottrell equation were used to obtain values for $D$ of $2.42 \times 10^{-5}$ and $7.42 \times 10^{-5} \mathrm{~cm}^{2} \mathrm{~s}^{-1}$ for levodopa and piroxicam, respectively.

The stability of the GCE/ZnO-Pd/CNTs was tested by keeping the suggested sensor at $\mathrm{pH}=7.0$ in PBS for 8 days and then recording cyclic voltammograms of the solution containing $400 \mu \mathrm{M}$ of levodopa and $200 \mu \mathrm{M}$ of piroxicam for comparison with cyclic voltammograms obtained before immersion (Fig. 9). The data indicated that the peak oxidation current of the two drugs decreased only slightly for the GCE/ ZnO-Pd/CNTs, which suggests that the GCE/ZnO-Pd/CNTs have good stability. The stability of the GCE/ZnO-Pd/CNTs over time was investigated for a period of 60 days (about 100 measurements). Comparison of the oxidation signals showed a small change in the levodopa and piroxicam signals $(\sim 4.8 \%)$ after storage of sensor in a laboratory, indicating good stability for the proposed sensor.

Fig. 10A shows the differential pulse voltammograms of the GCE/ZnO-Pd/CNTs at different concentrations of levodopa and piroxicam. As seen, separate oxidation signals at potentials of $\sim 180$ and $\sim 480 \mathrm{mV}$ were detected at the surface of the GCE/ZnO-Pd/CNTs relative to levodopa and piroxicam, respectively. The peak oxidation current at different levodopa and piroxicam concentrations showed a linear relationship of 0.6 to $100.0 \mu \mathrm{M}$ and 0.1 to $90.0 \mu \mathrm{M}$, respectively (Fig. 10B and C) with detection limits of $0.08 \mu \mathrm{M}$ and $0.04 \mu \mathrm{M}$, respectively.

The selectivity of the GCE/ZnO-Pd/CNTs was checked for simultaneous determination of levodopa and piroxicam in the presence of foreign species and showed an acceptable relative error of \pm 5 . Table 1 shows the data, which confirmed good selectivity of the GCE/ZnO-Pd/CNTs for the simultaneous determination of levodopa and piroxicam. The interference of ascorbic acid was resolved by the addition of $1.0 \mathrm{mM}$ ascorbic oxidase.

The ability of the GCE/ZnO-Pd/CNTs to detect levodopa and piroxicam in blood and urine samples was checked by the standard addition method. The data in Table 2 shows the good ability of GCE/ZnO-Pd/CNTs for analysis of levodopa and piroxicam in real samples.

\section{Conclusions}

In the current study, a highly sensitive voltammetric sensor was fabricated for the first time using a glassy carbon electrode modified with ZnO-Pd/CNT nanocomposite. The GCE/ZnO$\mathrm{Pd} / \mathrm{CNTs}$ were used for simultaneous determination of the presence of levodopa and piroxicam at 0.6 to $100.0 \mu \mathrm{M}$ and 0.1 to $90.0 \mu \mathrm{M}$, respectively. In the final step, GCE/ZnO-Pd/CNTs were successfully used to detect levodopa and piroxicam in blood and urine samples.

\section{Compliance with ethical standards}

- We confirm that all experiments were performed in compliance with relevant laws or guidelines.

- We confirm that all experiments followed institutional guidelines.

- We confirm institutional committee(s) approved the experiments.

- The urine sample was collected by corresponding author and he was agreeing with this experimental.

- This study was performed in strict accordance with the NIH guidelines for the care and use of laboratory animals (NIH Publication No. 85-23 Rev. 1985) and was approved by the Vice Chancellor for Research of Quchan University of Technology (Quchan, Iran).

\section{Conflicts of interest}

There is no conflicts of interest.

\section{References}

1 M. Ashjari, H. Karimi-Maleh, F. Ahmadpour, M. ShabaniNooshabadi, A. Sadrnia and M. A. Khalilzadeh, J. Taiwan Inst. Chem. Eng., 2017, 80, 989-996.

2 J. G. Manjunatha, J. Electrochem. Sci. Eng., 2017, 7, 39-49.

3 M. Lutfi Yola and N. Atar, Curr. Anal. Chem., 2017, 13, 13-17.

4 B. Hatamluyi and Z. Es' haghi, J. Electroanal. Chem., 2017, 801, 439-449.

5 M. Shabani-Nooshabadi and F. Tahernejad-Javazmi, RSC Adv., 2015, 5, 56255-56261. 
6 M. Tohidinia, M. Farsadrooh, S. Bahmanzadeh, N. Sabbaghi and M. Noroozifar, RSC Adv., 2018, 8, 1237-1245.

7 V. K. Gupta, S. Kumar, R. Singh, L. Singh, S. Shoora and B. Sethi, J. Mol. Liq., 2014, 195, 65-68.

8 H. Karimi-Maleh, F. Tahernejad-Javazmi, N. Atar, M. L. t. Yola, V. K. Gupta and A. A. Ensafi, Ind. Eng. Chem. Res., 2015, 54, 3634-3639.

9 K. Vinod, Analyst, 1995, 120, 495-498.

10 B. J. Sanghavi, J. A. Moore, J. L. Chávez, J. A. Hagen, N. KelleyLoughnane, C.-F. Chou and N. S. Swami, Biosens. Bioelectron., 2016, 78, 244-252.

11 M. L. Yola and N. Atar, J. Electrochem. Soc., 2017, 164, B223B229.

12 F. Tahernejad-Javazmi, M. Shabani-Nooshabadi and H. Karimi-Maleh, Talanta, 2018, 176, 208-213.

13 N. Atar, T. Eren, M. L. Yola, H. Karimi-Maleh and B. Demirdögen, RSC Adv., 2015, 5, 26402-26409.

14 M. L. Yola, V. K. Gupta, T. Eren, A. E. Şen and N. Atar, Electrochim. Acta, 2014, 120, 204-211.

15 V. K. Gupta, H. Karimi-Maleh and R. Sadegh, Int. J. Electrochem. Sci., 2015, 10, 303-316.

16 H. Karimi-Maleh, A. Bananezhad, M. R. Ganjali, P. Norouzi and A. Sadrnia, Appl. Surf. Sci., 2018, 441, 55-60.

17 A. L. Sanati, F. Faridbod and M. R. Ganjali, J. Mol. Liq., 2017, 241, 316-320.

18 F. Xiao, C. Ruan, L. Liu, R. Yan, F. Zhao and B. Zeng, Sens. Actuators, B, 2008, 134, 895-901.

19 A. L. Sanati and F. Faridbod, Int. J. Electrochem. Sci., 2017, 12, 7997-8005.

20 N. F. Atta, M. F. El-Kady and A. Galal, Anal. Biochem., 2010, 400, 78-88.

21 M. Sheikholeslami, J. Mol. Liq., 2018, 249, 739-746.

22 M. Sheikholeslami, J. Mol. Liq., 2018, 259, 424-438.

23 M. Sheikholeslami, J. Taiwan Inst. Chem. Eng., 2018, 86, 2541.

24 M. Sheikholeslami, J. Mol. Liq., 2018, 263, 303-315.
25 H. Karimi-Maleh, P. Biparva and M. Hatami, Biosens. Bioelectron., 2013, 48, 270-275.

26 H. Karimi-Maleh, A. F. Shojaei, K. Tabatabaeian, F. Karimi, S. Shakeri and R. Moradi, Biosens. Bioelectron., 2016, 86, 879-884.

27 M. A. Chamjangali, H. Kouhestani, F. Masdarolomoor and H. Daneshinejad, Sens. Actuators, B, 2015, 216, 384-393.

28 B. J. Sanghavi, W. Varhue, A. Rohani, K.-T. Liao, L. A. Bazydlo, C.-F. Chou and N. S. Swami, Lab Chip, 2015, 15, 4563-4570.

29 H. Karimi-Maleh, M. Hatami, R. Moradi, M. A. Khalilzadeh, S. Amiri and H. Sadeghifar, Microchim. Acta, 2016, 183, 29572964.

30 M. L. Yola, N. Atar, T. Eren, H. Karimi-Maleh and S. Wang, RSC Adv., 2015, 5, 65953-65962.

31 S. A. Alavi-Tabari, M. A. Khalilzadeh and H. Karimi-Maleh, J. Electroanal. Chem., 2018, 811, 84-88.

32 M. Bijad, H. Karimi-Maleh, M. Farsi and S.-A. Shahidi, Journal of Food Measurement and Characterization, 2018, 12, 634-640.

33 H. Dai, N. Wang, D. Wang, X. Zhang, H. Ma and M. Lin, Microchim. Acta, 2016, 183, 3053-3059.

34 S. Wei, F. Zhao, Z. Xu and B. Zeng, Microchim. Acta, 2006, 152, 285-290.

35 G. L. Turdean and G. Szabo, Food Chem., 2015, 179, 325-330.

36 T. Tavana, M. A. Khalilzadeh, H. Karimi-Maleh, A. A. Ensafi, H. Beitollahi and D. Zareyee, J. Mol. Liq., 2012, 168, 69-74.

37 B. Wu, D. Hu, Y. Kuang, B. Liu, X. Zhang and J. Chen, Angew. Chem., Int. Ed., 2009, 121, 4845-4848.

38 H. Karimi-Maleh, M. Shojaei, F. Amini and A. Akbari, Electroanalysis, 2017, 29, 1854-1859.

39 D. Robertson, N. Wood, H. Everest, K. Monks, D. Waller, A. Renwick and C. George, Br. J. Clin. Pharmacol., 1989, 28, 61-69.

40 A. M. Teema, S. A. Zaitone and Y. M. Moustafa, Neuropharmacology, 2016, 107, 432-450. 